\title{
Bases teóricas para una hipótesis no canónica sobre el origen de la herramienta lingüística humana
}

\author{
JOSÉ LUIS GUIJARRO MORALES \\ Universidad de Cádiz \\ Facultad de Filosofía y Letras \\ Avda. Gómez Ulla S/N \\ 11003 Cádiz \\ E-mail: joseluis.guijarro@uca.es \\ Tel. +34956011613 \\ Fax. +34 956015505
}

BASES TEÓRICAS PARA UNA HIPÓTESIS NO CANÓNICA SOBRE EL ORIGEN DE LA HERRAMIENTA LINGÜÍSTICA HUMANA

RESUMEN: Ante los problemas que present la hipótesis de que el lenguaje humano es una evolución de la capacidad comunicativa del mismo (p.e., su probable aparición súbita (Chomsky), su complejidad universal (Pinker), el hecho de que infra-determine los mensajes comunicados (Sperber \& Wilson), etc.), se ofrece otra alternativa en la que se intenta refinar el uso terminológico de ciertos conceptos, tratando de evitar algunos de estos problemas, y proponiendo, para ello, una concepción evolutiva no sólo basada en la selección natura (Darwin), sino también en la de la endosimbiosis (Margulis)

PALABRAS CLAVES: lenguaje (lengua, idioma): comunicación; evolución; selección natural; endosimbiosis.

SUMARIO: 1. Introducción. 2. La evolución de las especies vivas. 3. Bases teóricas en las que se ha formado la presente hipótesis. 4. Hipótesis central de este trabajo a partir de las anteriore consideraciones.
THEORETICAL BASES OF A POSSIBLE NONCANONICAL HYPOTHESIS ON THE ORIGINS OF THE HUMAN LINGUISTIC TOOL

ABSTRACT: The canonical hypothesis argues that human language evolved from simpler communicative acts in a manner non-specified, since there are no primitive languages in the World which could give us hints as to the steps it may have taken in its evolution. I think that creating a new hypothesis based on a serious attempt to reach the levels of adequacy proposed by Chomsky, and on adopting the endosymbiotic evolutionary mechanism proposed by Margulis, could easily do away with those (and a host of others) theoretical problems.

KEY WORDS: language; communication; evolution; natural selection; endosybiosis.

SUMMARY: 1. Introduction 2. The evolution of living species. 3. Theoretical basis on which this hypothesis has formed. 4. Central hypothesis of this work from the foregoing.
BASES THEORIQUES D'UNE POSSIBLE HYPOTHESE NON CANONIQUE SUR L'ORIGINE DE L'OUTIL LINGUISTIQUE HUMAIN

RÉSUMÉ: L'hypothèse canonique qui veut que le langage humain soit une évolution de la capacité communicative humaine présente des problèmes qui, il me semble, peuvent être effacé si on adopte une autre hypothèse qui, fondée su l'utilisation approprié de la terminologie conceptuelle, essaye d'expliquer cette évolution non seulement par le mécanisme darwinien de la sélection naturelle mais en ajoutant celui de l'endosymbiose proposé par Lynn Margulis.

MOTS CLÉS: langage (langue) communication; évolution; sélection naturelle; endosybiose.

SOMMAIRE: 1. Introduction. 2. L'évolution des espèces vivantes. 3 . Les bases théoriques sur lesquelles cette hypothèse a formé. 4. Hypothèse centrale de ce travail de ce qui précède.

$\begin{array}{ll}\text { Fecha de Recepción } & 01 / 03 / 2011 \\ \text { Fecha de Revisión } & 11 / 04 / 2011 \\ \text { Fecha de Aceptación } & 29 / 05 / 2011 \\ \text { Fecha de Publicación } & 01 / 12 / 2011\end{array}$




\section{Bases teóricas para una hipótesis no canónica sobre el origen de la herramienta lingüística humana ${ }^{1}$}

JOSÉ LUIS GUIJARRO MORALES

\section{INTRODUCCIÓN}

Los estatutos de la Sociedad Lingüística de París aprobada por Orden Ministerial del 8 de marzo de 1866, después de indicar los objetivos que se le atribuye en su artículo 1, establecen seguida y taxativamente, en su artículo 2, aquello que se consideraba absurdo intentar tratar por los investigadores que iban a formar parte y trabajar en ella.

Artículo $1^{\circ}$ : La Sociedad Lingüística tiene por objeto el estudio de las lenguas, las leyendas, tradiciones, costumbres documentos, que puedan ayudar la ciencia etnográfica. Cualquier otro objeto de estudio está rigurosamente prohibido.

Artículo $2^{\circ}$ : La Sociedad no admite ninguna comunicación que se ocupe, sea del origen del lenguaje, sea de la creación de un idioma universal ${ }^{2}$

(NOTA BENE: Todas las traducciones que aparecen en el cuerpo de este artículo son mías. Los textos originales van a pie de página.)

Tal y como se entendía en aquel momento, pues, se podía hablar de muchos temas relacionados con la lingüística (las leyendas, las tradiciones, los documentos etnográficos, etc.) evitando genéricamente otros. Pero, además, prohibía expresamente y explícitamente en el segundo artículo que sus miembros se ocuparan de los orígenes o de la creación de un idioma universal. Se pensaba que cualquier elucubración sobre estos temas carecía de la suficiente entidad científica para que los investigadores con mucha imaginación perdieran su tiempo y se lo hicieran perder a los demás. Debido a ello, la prohibición expresa de los franceses fue secundada, universal pero silenciosamente, por los demás investigadores, en especial por los anglosajones, germanos e hispanos.

Siglo y medio después, cuando la teoría de la gramática generativa propuesta por Noam Chomsky ha dado un vuelco a esta visión de la lingüística y la cuestión de los universales lingüísticos (no confundir con la creación de un idioma universal) que supuestamente se transmiten en la estructura mental de nuestra especie es un tema central de debate acalorado, han surgido varias hipótesis interesantes sobre el posible origen del lenguaje humano que intentan adaptarse a los supuestos básicos de algunos modelos lingüísticos, antropológicos y biológicos enmarcados o no dentro del esquema de la evolución específica por selección natural.

\footnotetext{
${ }^{1}$ El farragoso título de este trabajo podría haber sido simplemente "Hipótesis no-canónica sobre el origen del lenguaje humano", pero, por algunas de las razones que veremos a continuación, he preferido construirlo de esta manera para no llamar a engaño o, incluso, caer en contradicciones.

${ }^{2}$ Article 1. - La Société de Linguistique a pour but l'étude des langues, celle des légendes, traditions, coutumes, documents, pouvant éclairer la science ethnographique. Tout autre objet d'études est rigoureusement interdit.

Article 2. - La Société n'admet aucune communication concernant, soit l'origine du langage soit la création d'une langue universelle.
} 
En este trabajo pretendo presentar una hipótesis no canónica sobre el origen de esta facultad humana que, de manera natural, haga desaparecer algunos de los problemas hasta hoy en día no resueltos por las hipótesis más extendidas actualmente que consideran la comunicación humana ancestral como el primer paso evolutivo a tener en cuenta en la aparición de nuestra herramienta lingüística. Si esta idea del origen comunicativo del lenguaje fuera tan evidente como cree la mayoría de los investigadores, haría falta explicar muy claramente por qué esta evolución ocurrió sólo en nuestra especie. También necesitaríamos poder responder a la asombrosa cuestión de por qué no se tiene noticia, ni se ha encontrado jamás, ni siquiera en las sociedades que etnocéntricamente consideramos primitivas, un idioma menos complejo y más primario que los que ahora conocemos y usamos. Finalmente, la hipótesis que presento podría explicar eventualmente el por qué la utilización de un código lingǘstico como herramienta para completar nuestros actos comunicativos de manera tan adecuada, hace posible, además, que al realizarlos, no sólo apuntemos a cosas (como parece que han logrado algunos individuos de otras especies laboriosamente amaestrados por investigadores de nuestra especie) sino a estados cognitivos complejos que, por el momento, no se han podido demostrar en las comunicaciones no humanas, a pesar de algunos resultados cuya interpretación no resulta siempre absolutamente convincente.

Por todo ello, creo que mi hipótesis evolutiva haría desaparecer estos y otros problemas con la misma facilidad que hacemos desaparecer el puño abriendo nuestra mano. Es decir, considerando el proceso evolutivo desde un punto de vista más abierto que el que generalmente se utiliza. Precisamente, para mostrar lo que quiero decir, empezaré por hacer un resumen apresurado de la teoría de la evolución tal y como pienso que debería entenderse.

\section{LA EVOLUCIÓN DE LAS ESPECIES VIVAS}

\subsection{LAS EXPANSIONES METAFÓRICAS DE ESTE CONCEPTO}

El concepto de la evolución se ha ampliado de tal manera, a causa de su poder explicativo en biología, que se hace necesario matizar la terminología para adecuarla observacionalmente a cada realidad que se intenta inscribir en el marco de la teoría.

En efecto, si tenemos en cuenta su marco original, la teoría de la evolución se aplicó desde el comienzo a datos biológicos. Es decir, este tipo de análisis era aplicable descriptiva y explicativamente a organismos y órganos de los seres vivientes que, a medida que mejoraban sus funciones de reproducción y supervivencia, se iban haciendo más y más complejos hereditariamente y así constituían nuevos objetos en el inventario de la vida de nuestro planeta. Por ello, Darwin la cualificó, muy consecuentemente, como la evolución de las especies que, como sabemos, es el título de su libro en el que expuso su teoría.

La potencia explicativa de la teoría fue tan grande que, a pesar de sus muchos detractores viscerales, varios investigadores trataron de adaptarla a otros campos de estudio usando metáforas más o menos apropiadas. Así surgió, por ejemplo, el llamado darwinismo social que se ha considerado durante mucho tiempo una pseudociencia bastante perniciosa, ya que, al centrarse en el principio de supervivencia del más fuerte, ha servido para fundamentar con pretensiones de seriedad científica actitudes racistas y machistas responsables de holocaustos históricos o de situaciones de injusticia flagrante que, en realidad, carecen de toda justificación. Más éxito, sin embargo, ha tenido la llamada sociobiología, propuesta por Edward O. Wilson, que 
pensaba que, aunque es cierto que la diversidad comportamental de los seres humanos es debida a factores culturales, alguno de estos comportamientos, sin embargo, parece ser innato (por ejemplo, la rápida adquisición lingüística típica de la especie humana, el altruismo, los sentimientos religiosos, etc.), aunque también ha sido duramente criticada por las mismas razones que el darwinismo social.

Hay que tener en cuenta, no obstante, que el marco evolutivo ya estaba esbozado cuando Darwin irrumpió en él. La aportación de este investigador fue describir el mecanismo por el que dicha evolución se realizaba, al que llamó la selección natural. La descripción de este mecanismo, no obstante, ha cambiado desde que Darwin la realizó hasta hoy en día en que los mecanismos genéticos (descubiertos por Georg Mendel) se conocen y se entienden mejor que entonces. Los investigadores que han aunado estos conocimientos con la descripción del proceso de selección natural son los que hoy en día se conocen como neo-darwinistas ${ }^{3}$. Alguno de estos investigadores, de los cuales, el más prolífico y conocido es Richard Dawkins, han intentado metaforizar el concepto de la unidad genética (i.e., los genes) responsable de la evolución biológica con otra unidad memorística (i.e., los memes) que, de esta manera, podría aportar la base para una descripción causal, y por tanto, científica, de los cambios culturales.

No obstante, tradicionalmente, los cambios que han existido en los conocimientos aprendidos socialmente, como pueden ser las matemáticas, la medicina, etc., y los que tienen que ver con cambios en comportamientos, tales como el manejo de vehículos (desde la carretilla hasta el cohete espacial), etc., se han enmarcado en lo que comúnmente se conoce como historia. Es decir, a nadie se le ocurre hablar de la evolución de nuestros conocimientos en informática, pongamos por caso, ya que no parece que se pueda presuponer una base biológica que haga posible dicho conocimiento. Cuando deseamos describir los cambios evidentes que se están produciendo en algún campo social, hablamos de su historia, no de su evolución.

Sin embargo, hay algunas zonas de indecisión a la hora de hablar de historia o de evolución. Un caso que nos toca de cerca es el de los idiomas. El español que yo escribo hoy en día es claramente diferente del escribía Gonzalo de Berceo, pongamos por caso. ¿Podemos decir que ha habido una evolución del español? ¿O simplemente hablaremos de la historia del idioma español? Creo que, en realidad, no se puede hablar de una evolución propiamente dicha en cada uno de los idiomas del mundo. Existe, es cierto, una evolución en la aparición del órgano lingüístico. Y, probablemente, exista también una evolución en el dispositivo mental que consigue formalizar estímulos para poder almacenarlos mentalmente. Pero, al menos en este trabajo, voy a proponer que los idiomas naturales queden fuera del análisis evolutivo, como veremos más abajo.

El esfuerzo de Dawkins al metaforizar esas unidades meméticas como si fueran unidades biológicas genéticas se comprende como intento de dar a la historia un carácter causal y, por tanto, científico. Pero, puestos a metaforizar, parece más útil y menos extremo, enmarcar los cambios que acaecen en las representaciones mentales en un estudio de epidemiología ${ }^{4}$. En la investigación epidemiológica médica, los análisis se centran en dos aspectos claves de los

\footnotetext{
${ }^{3}$ Existen, sin embargo, voces acreditadas que reservan el término neo-darwinismo para apuntar al concepto que originariamente describió George Romanes en 1865 refiriéndose a los trabajos de Alfred Russell Wallace y August Weisemann que establecieron que era la selección natural y no los cambios adquiridos por cada individuo (como creían Lamarck y sus seguidores) el único motor de estos cambios (cf. Mayr, 1984). No obstante, es común usar este nombre para el darwinismo contemporáneo en general.

${ }^{4}$ Cf. D. Sperber (2000).
} 
contagios: las características de las bacterias o virus que los hacen tan contagiosos y, también, en los condicionantes del entorno que ayudan a ese contagio. Algo similar podría intentarse al estudiar la expansión de una idea, un sentimiento o un hábito en un núcleo social determinado; si ese tipo de investigación de doble vertiente (es decir, qué tipo de idea estamos analizando y en qué entorno social se ha diseminado) resultara posible, estaríamos ante una investigación de tipo estrictamente causal y, por tanto, científica.

\subsection{CONSECUENCIAS DEL CARÁCTER CIENTÍFICO Y NO RELIGIOSO DEL DARWINISMO Y NEO-DARWINISMO}

La diferencia fundamental entre los asertos religiosos y los científicos es, dejando aparte su manera de llegar a ellos, el tipo de fuerza que desean obtener. Los asertos religiosos pretenden establecer una verdad inmutable que, por tanto, resulta ser la misma en sus orígenes y en el momento presente. Los asertos científicos, por otra parte, intentan describir y explicar fenómenos con arreglo a la panoplia de conocimientos relevantes que en cada momento tenemos a nuestro alcance. Por tanto, a medida que nuestros conocimientos se amplían, los análisis pueden y deben cambiar.

La teoría de Darwin, como vimos antes, es una creación científica y, por lo tanto, no es un dogma inamovible. De hecho, como también indicamos, los conocimientos de los procesos genéticos que se han ido desarrollando a partir de los trabajos de Mendel hasta los de Watson y Cricks, tienen por fuerza que cambiar algunos de los aspectos de la teoría de la selección natural. Hemos visto que el neo-darwinismo es, precisamente, una adaptación de la teoría original de Darwin a estos conocimientos genéticos, pero hemos de seguir considerando la aparición de nuevos conocimientos y ver si pueden, o cambiar algunos supuestos de dicha teoría, o, al menos adaptarla a ellos.

No soy biólogo evolutivo, ni tengo una base sólida para proponer estos cambios, pero puedo apuntar a ciertas posibilidades documentadas que servirían de base para la hipótesis evolutiva que quiero presentar en este trabajo. Al fin y al cabo, no hago sino seguir la indicación llena de sentido común de otro conocido investigador interesado en el origen del lenguaje, D. Bickerton (2003: 79) que afirma que, “[...] cualquier persona con una inteligencia corriente debería, con buena voluntad y poco esfuerzo, ser capaz de conocer suficientes datos en todas las disciplinas relevantes para evitar caer en errores garrafales ${ }^{5}$."

Espero, por tanto, estar a la altura de las circunstancias y no cometer errores de bulto que invaliden la hipótesis evolutiva antes de calibrarla a la luz de los datos que me propongo aportar seguidamente.

En el número 14 del Journal of Theoretical Biology aparecido en 1967, una investigadora prácticamente desconocida, Lynn Alexander, escribió un importante artículo (firmado con el apellido de su entonces famoso marido, el astrofísico Carl Sagan) que fue un paso de gigante en biología. El resumen inicial del artículo comenzaba con la siguiente afirmación:

Se presenta una teoría del origen de las células eucariotas (células complejas que se dividen por los procesos de la mitosis clásica). Se parte de la hipótesis de que tres orgánulos, las

\footnotetext{
5 “[...] anyone of average intelligence should, given goodwill and a little effort, be able to master enough of the literature in all relevant disciplines to avoid making gross errors” (D. Bickerton, 2003: 79). La traducción es mía.
} 
mitocondrias, los plásticos fotosintéticos y los cuerpos basales $(9+2)$ de los flagelos fueron inicialmente células de vida independiente (procairotas) ${ }^{6}$.

Puede parecer oscuro para los no iniciados, pero en realidad lo que la autora propone es que la complejidad biológica (la de las células eucariotas) no tuvo por qué aparecer solamente siguiendo el proceso gradual y totalmente caprichoso que establece la teoría de la selección natural, sino que también podría haber resultado de la unión provechosa de dos o más entidades ya existentes (las procairotas). La selección natural conseguiría que algunas de estas nuevas entidades complejas que hubieran conseguido mejorar las características de supervivencia se convirtieran en nuevos organismos del inventario vital. Además, quizá fuera posible determinar los pasos de su evolución posterior como unidad simbiótica.

Esta teoría, que se conoce como SET (Serial Endosymbiosis Theory), se ha estimado casi universalmente, quizás con razón, como contraria a la noción de absoluta aleatoriedad que fundamenta la teoría de la selección natural, basada en mutaciones infundadas, de las cuales, sólo algunas logran aumentar la posibilidad de supervivencia y de reproducción, siendo ellas, únicamente, las que se fijan y hacen evolucionar los organismos. Sin embargo, en una interpretación más amplia, el encuentro de dos o más entidades cuyas características pudieran ser mutuamente provechosas es, también, en cierto sentido, un acontecimiento aleatorio, aunque, luego, el proceso de ensamblaje de ambas en una unidad más compleja sí que estaría fundamentado por las ventajas que dicha unión aporta ${ }^{7}$.

Debido a los ataques más o menos viscerales que la teoría de la selección natural ha recibido desde su aparición, cualquier idea que pueda contradecirla es puesta inmediatamente en solfa, si no atacada despiadadamente por los darwinianos. De hecho, Lynn Alexander (posteriormente, Lynn Sagan, como hemos visto) tuvo que sufrir varias negativas a publicar su interesante y documentado texto. $\mathrm{Y}$, una vez que fue publicado, recibió duras críticas de parte de la mayoría de la comunidad científica del momento. Sin embargo, la investigadora no se arredró y siguió publicando sus trabajos cada vez con mayor aporte de datos, aunque volvió a cambiar de nombre, ya que se casó de nuevo y, hoy en día, la SET se atribuye definitivamente a Lynn Margulis y muchos de sus postulados se explican ya en las universidades más prestigiosas -aunque hay que reconocer que no es una teoría universalmente aceptada ${ }^{8}$.

Sin embargo, si lo fuera, sólo abundaría en la idea de que nadie, ni siquiera el mismísimo Darwin, son infalibles y sus teorías pueden ser falsadas o, al menos, modificadas sin que se merme en nada su asombroso genio investigador.

\section{BASES TEÓRICAS EN LAS QUE SE HA FORMADO LA PRESENTE HIPÓTESIS}

Aunque, naturalmente, no puedo resumir todas las ideas que me han llevado a imaginar esta hipótesis sobre el origen de nuestra herramienta lingüística, creo que sin las tres que

\footnotetext{
${ }^{6}$ A theory of the origin of eukaryotic cells ("higher" cells which divide by classical mitosis) is presented. By hypothesis, three fundamental organelles: the mitochondria, the photosynthetic plastids and the $(9+2)$ basal bodies of flagella were themselves once free-living (prokaryotic) cells (C. Sagan, 1967).

${ }^{7}$ Seguramente, debido a mi falta de preparación en este tipo de marco evolutivo biológico, no veo mucha diferencia entre la aleatoriedad de las mutaciones y su fundamentada fijación biológica debido a las ventajas que pueda aportar y el propuesto proceso de endosimbiosis, tal y como aquí lo hemos esquematizado. De todas maneras, esta interpretación (sea o no errónea) es escasamente relevante para apoyar la hipótesis central de este trabajo.

${ }^{8}$ Cf., Sanpedro (2007).
} 
expongo a continuación nunca la hubiera formulado tal cual lo haré al final de este trabajo. Por ello, pienso que es conveniente explicarlas antes de desarrollar mi idea?

\subsection{LA APARICIÓN SÚBITA DE LA HERRAMIENTA LINGÜÍSTICA EN LA ESPECIE HUMANA}

En el trabajo que Noam Chomky publicó junto con los biólogos Marc Hauser y Tecumseh Fitch ${ }^{10}$ se distingue por primera vez entre la facultad amplia del lenguaje (FAL) ${ }^{11}$ que contiene todas las características no exclusivamente humanas del lenguaje, y la facultad reducida del lenguaje (FRL) ${ }^{12}$ que sería la específicamente humana y que, según estos investigadores, constaría de sólo una característica básica de la que luego se derivarían todas las demás que hacen que nuestra herramienta lingüística sea tan efectiva para ayudarnos a ser muy precisos en nuestros actos comunicativos. Según estos autores, esta FRL aparece súbitamente en la especie humana por causas que es imposible determinar actualmente. No vamos a entrar en la polémica que surgió a partir de esta idea central (sobre todo, Jackendoff y Pinker, 2005; Fitch, Hauser y Chomsky, 2005) porque no es éste el tema que nos ocupa. Sin embargo, quiero resaltar que, desde mi punto de vista, la distinción, aunque obligada por la pobreza terminológica del inglés, no resulta muy clara. ¿A qué estamos apuntando con FAL que sea distinto de lo que estamos apuntando con FRL? ¿Se trata de un mismo concepto, visto desde una perspectiva más amplia y otro desde una más restringida? ¿Son, pues, dos punteros terminológicos que apuntan a un mismo lugar? Se podría argumentar a favor de esta manera de apuntar, evidentemente, pero resultaría algo muy poco explícito y, como ha ocurrido en la subsiguiente discusión a la que acabo de apuntar, alguien podría meter en el saco de la FRL otras características que también parecen exclusivas de esta facultad específicamente humana como los sistemas fonológicos y los morfológicos, los casos y la concordancia, así como las especializaciones anatómicas que han formado el sistema auditivo humano ${ }^{13}$. Tal y como se presenta en algunos textos, no existe una manera clara de distinguir entre estos términos; no hay, por ello, consenso a la hora de establecer cuál es la mejor descripción de los mismos, con lo que, o caemos en un reduccionismo no explicativo, o creamos un cajón de sastre poco ajustado con todo aquello que consideramos características exclusivamente humanas de nuestra herramienta lingüística. Chomsky y sus colaboradores apuntan a esta confusión terminológica, en su respuesta a Pinker y Jackendoff

Parte importante de la crítica de S. Pinker y R. Jackendoff (PJ) se basa en que difuminan la distinción, amplia o reducida, que hicimos al interpretar el término "facultad del lenguaje". Aunque PJ están de acuerdo con esta distinción, muchos de sus argumentos parecen derivarse

\footnotetext{
${ }^{9}$ En realidad, este trabajo surgió de una discusión on line con la autora de una memoria de MSC, titulada Abrupt versus Gradual Evolution of Language and the Case for Semilanguage, Cory Stade (2009), que se puede ver en http://www.lingforum.com/forum/viewtopic.php?t=1681. La autora y yo no coincidimos en casi nada, pero la discusión fue muy productiva y sirvió para afianzar mis ideas. Creo que es de justicia reconocerlo aquí.

${ }^{10}$ Hauser, M. \& al, 2002

${ }^{11}$ En las siglas inglesas, en cambio, se conoce como BLF, correspondiente a broad language faculty.

${ }^{12}$ Que en inglés se llama narrow faculty of language (NFL).

${ }^{13}$ Cf.. S. Pinker y R. Jackendoff, 2005.
} 
directamente de no hacerla ellos mismos, o de reconocer dónde la hacemos nosotros. Por ello empezaremos clarificando esta distinción y su importancia ${ }^{14}$

La primera consideración, pues, es que en este tema uno ha de ser absolutamente claro en aquello que trata de señalar, describir y explicar, para evitar malentendidos y debates terminológicos. Para ello, utilizaré otra idea chomskyana que expondré más adelante en este trabajo y que, creo, me permitirá circunscribir el problema a unos límites más precisos.

\subsection{LA IDEA FUNCIONALISTA DE LA EVOLUCIÓN COGNITIVA}

Al leer la idea del filósofo norteamericano, Jerry Fodor, sobre cómo enfrentarnos con el análisis y descripción de la evolución de los procesos mentales, pensé que se abría una posibilidad para salvar el escollo que señalan los autores del trabajo que acabo de comentar. Según Fodor (y, al parecer otros filósofos ${ }^{15}$ ) hemos de tener en cuenta que las unidades cognitivas que vamos a analizar pertenecen funcionalmente a la estructura del procesamiento de la información que llamamos mente humana. Es decir, lo que hace evolucionar los aspectos mentales es su mejor funcionamiento para solucionar ciertos problemas, con lo que habrá que averiguar cuáles son esos problemas y cómo se han solucionado de manera cognitiva. Por tanto, la neurofisiología, que se ha organizado tal y como hoy nos la encontramos sólo porque es capaz de realizar la organización cognitiva de manera física -y no al revés, como creen algunos- no nos sirve para empezar a entender la evolución de los procesos cognitivos. La idea de que, por ejemplo, la parición de la FLR se debe a un aumento considerable del peso del cerebro humano, que ha formado por causalidad un centro lingüístico específico en nuestra especie, no ayuda a entender el origen de tal centro. Tengamos en cuenta, pues, que la función del cerebro que llamamos mente es informacional, y que, por tanto, su estructura rica y compleja solamente se percibe si somos capaces de considerarla desde el punto de vista cognitivo (que es describible como un sistema de computaciones); si describimos el cerebro neurofisiológicamente, seguro que haremos descubrimientos muy interesantes, pero su dimensión adaptativa será invisible hasta que sus mecanismos no sean expresados en un lenguaje que resalte su función informacional -un lenguaje, naturalmente, computacional. Lo que las matemáticas han sido para los estudios de física (un lenguaje que descubre relaciones interesantes), la computación cognitiva puede ser para los estudios de nuestra mente. Hay que tener claro, pues, que las relaciones computacionales pueden y deben describirse con precisión, independientemente de su realidad física. Para entendernos, podemos afirmar que un programa computacional es un conjunto de relaciones invariables entre las entradas o aductos (inputs) informativos y las salidas o eductos (outputs) comportamentales. Como es natural, repetimos, lo que realmente necesitamos describir y entender es todo este sistema cognitivo. El cerebro, en cambio, que es lo que les interesa a los neurobiólogos, se adapta a esas necesidades a través de pasos evolutivos, de tal manera que, a veces, si alguno de sus componentes físicos se daña, es

\footnotetext{
${ }^{14}$ One main thrust of PJ's critique results from their blurring the distinction we drew between broad and narrow interpretations of the term "faculty of language." Although PJ endorse this distinction, many of their arguments appear to result directly from a failure to make it themselves, or to perceive where we were making it. We thus start by clarifying this distinction, and its importance (Fitch, W. Tecumseh, Mark D. Hauser y Noam A. Chomsky: 2005)

15 Por ejemplo, el filósofo T. Burge (2010) critica ferozmente la manía generalizada de tratar de explicar fenómenos psicológicos mediante descripciones fisiológicas que, por eso mismo, por confundir los niveles, acaban por no explicar nada.
} 
capaz de realizar funciones similares en otra parte física del mismo; por tanto, para nosotros, no es esencial su estudio por el momento ${ }^{16}$.

Según Fodor, la estructura de la mente se puede imaginar esquemáticamente como compuesta por dos sistemas computacionales básicos, (1) el que forman lo que él llama módulos cognitivos, que serían innatos y sus computaciones muy constreñidas, y (2) una parte cognitiva central y general que sería la encargada de aunar los resultados que hubieran surgido de los módulos y así manipularlos conjuntamente. Para este autor, el lenguaje sería uno de estos módulos. Por tanto, podemos afinar más, y explicitar que lo que nos interesa en este trabajo es proponer una hipótesis sobre su origen (modular) en la mente humana ya que es un órgano que sólo aparece en la especie humana.; un órgano que no es realmente fisiológico, sino un centro de operaciones prefijadas que funcionan de manera analizable $y$, por ende, describible ${ }^{17}$.

Uno de los más prolíficos investigadores actuales que se han ocupado del origen del lenguaje, el ya mencionado Dereck Bickerton, abunda en esta idea funcionalista:

Si buscamos "ser humano" en la Enciclopedia Británica de la red, encontraremos la descripción siguiente: "Primate portador de cultura que es anatómicamente similar y está muy relacionado con los grandes simios, pero que se distingue de ellos por tener un cerebro mucho más desarrollado y la capacidad resultante para utilizar un lenguaje y un razonamiento abstractos". ¡Vaya con "resultante”! Se trata de una de esas expresiones que parecen tener sentido, como la de "el sol se levanta por el este", hasta que uno se pregunta si eso es lo que realmente ocurre.

Darwin sabía hace un siglo y medio que la Enciclopedia lo decía al revés. Que no es el cerebro altamente desarrollado el que nos permitía gozar de lenguaje y de pensamiento abstracto, sino que es el lenguaje el que nos permite tener pensamiento abstracto y un cerebro muy desarrollado ${ }^{18}$.

Para resumir, otra consideración básica para mi hipótesis es la idea funcionalista que debe guiar nuestra descripción evolutiva de la herramienta lingüística que nos distingue de las demás especies.

\subsection{CARACTERÍSTICAS DE LA FUNCIÓN COMUNICATIVA DESDE EL PUNTO DE VISTA COGNITIVO}

La lingüista inglesa, Deirdre Wilson, junto al antropólogo cognitivo francés, Dan Sperber han dedicado sus esfuerzos investigadores a describir lo que ocurre en la comunicación de los seres humanos actuales. Han bautizado su teoría con el mandato de la máxima conversacional

\footnotetext{
${ }^{16}$ Cf. J. Fodor, 1983, 1985, etc.

17 Chomsky tuvo que cambiar el término competencia para evitar las interpretaciones dudosas que esa palabra connotaba, y la llamó órgano, que también tiene connotaciones (en este caso fisiológicas) que no son tan graves al interpretarse con arreglo a ellas.

18 Look up "human being" in the online Encyclopedia Britannica and you'll find "a culture-bearing primate that is anatomically similar and related to the other great apes but is distinguished by a more highly developed brain and a resultant capacity for abstract speech and abstract reasoning". "Resultant" indeed! This is one of those remarks that seem to make sense, like "the sun rises in the east", until you ask yourself, is that what really happened?

Darwin knew a century and half ago that the Encyclopedia had it backwards - that it wasn't a "highly developed brain" that gave us language and abstract thought, but language that gave us abstract thought and a highly developed brain (D. Bickerton, 2009: 5).
} 
de la relación que propuso Paul Grice, sé relevante, que, según dicho autor, si alguna vez resultara bien descrita, acabaría con todas las demás ${ }^{19}$. En efecto, la Teoría de la Relevancia lo consigue plenamente cambiando el marco social de análisis en el que se movía Grice por el mental, proponiendo que esa relevancia sea considerada más bien un principio cognitivo básico, en vez de una máxima o indicación de buenas prácticas sociales.

Este principio puede también funcionar cognitivamente en otras especies, ya que lo describen como el esfuerzo mínimo (haciendo hincapié en esta condición mínima) que se necesita para conseguir algún objetivo. Es decir, algo es relevante si consigue un beneficio al menor costo posible; si empleamos mucho esfuerzo superfluo, lo conseguido, argumentan Sperber y Wilson, puede dejar de ser relevante. Se trata, en otras palabras, de lo que tradicionalmente se conoce como la ley del mínimo esfuerzo que es la que normalmente suele guiar los comportamientos de los individuos de las especies vivas.

Sperber y Wilson distinguen entre la tendencia natural a conseguir la máxima relevancia posible a lo largo de la vida de cada individuo y argumentan que es más difícil describirla que la que ellos llaman tendencia a la relevancia óptima. Esta última es la que ellos analizan y describen en su trabajo, ya que depende de dos factores muy precisos en cada ocasión: la que proporciona el contexto donde se está actuando (no es lo mismo leer una novela para pasar el rato que leerla para hacer una crítica literaria, o un trabajo de investigación sobre ella) y la que tiene que ver con los deseos e intenciones del individuo que está actuando en un momento dado (no es lo mismo coger el autobús para ir a trabajar todos los días que cogerlo para encontrarte con la pareja de tu vida en una única ocasión). En estos casos puntuales es bastante sencillo conseguir una descripción algorítmica de la ratio existente entre el esfuerzo a realizar y los efectos beneficiosos que se espera obtener. En el momento en el que se considera que los objetivos se han alcanzado, no se suele realizar ningún esfuerzo adicional.

Para estos autores, la comunicación en general sería el proceso por el cual, mediante la realización de una serie de comportamientos intencionales se apuntara a la manifestación pública de algunas de las representaciones privadas de los comunicantes. Antes de seguir, tengamos en cuenta dos aspectos de esta somera descripción.

Es importante fijarse en la condición intencional de los comportamientos para considerar que una actuación sea o no comunicativa. Por tanto, el comportamiento no intencional, aunque puede ser interpretado y resultar informativo para otros, no es estrictamente un caso de comunicación. Las micciones caninas, por ejemplo, pueden considerarse comunicativas si se hacen para marcar el territorio; en cambio, las que desahogan la vejiga solamente, aunque informan sobre la existencia de otro perro, no son realmente actos de comunicación. En nuestra propia especie, los andares de un borracho no comunican (aunque informan) del estado etílico del individuo, el discurso entrecortado y demasiado rápido de una persona no comunica (pero informa) sobre el nerviosismo de esa persona, etc. Sólo si esos comportamientos se realizan intencionalmente (por ejemplo, con intención de engañar a alguien) se convierten en realmente comunicativos. Según esta idea, por tanto, los comportamientos de algunos animales que carecen de intención nunca comunican sino que

\footnotetext{
${ }^{19}$ Por eso no se comprende la sorprendente tendencia de varias investigadoras e investigadores actuales, que asumen la teoría de la relevancia, a seguir aumentando el número inicial de máximas conversacionales que imaginó Grice, como la llamada de la cortesía, por ejemplo, que es un caso típico de inflación teórica cuyos efectos explicativos son nimios comparados con el esfuerzo investigador que cuesta mantenerla en candelero; tal parece que estas investigadoras e investigadores están inmersos en una contradicción casi existencial sin percatarse de ello.
} 
informan de que algo sucede, como lo hace el humo que nos indica que hay fuego.

Así expresado parece muy claro; sin embargo, ¿qué es realmente la intención? Supongamos que, para empezar a hablar de ella de una manera explícita, apuntamos con esa palabra al resultado de incrustar una representación no existente todavía en el entorno físico del individuo dentro de otra de primer grado del tipo [deseo ...], conjuntándola al mismo tiempo con otra representación de los pasos comportamentales que se han de hacer para alcanzar tal deseo. Si se acepta esta caracterización hay casos de transmisión de información que claramente no son intencionales. Una perra en celo no se representa su posible cubrimiento por parte de un macho al exhalar su olor característico como medida para lograrlo. Sin embargo, hay otros comportamientos animales qué sí podrían considerarse comunicativos por transmitir información de manera intencional, como hemos visto. Avanzando un nivel más, algunas aves (sobre todo, las limícolas, como chorlitos, avefrías, etc.), intentan apartar al posible depredador de su nido terrestre por medio de un comportamiento que, visto antropocéntricamente, al menos, es lisa y llanamente un engaño. En efecto, inician un comportamiento de aleteo terrestre que indica a los depredadores que es un animal herido, pero lo hacen en dirección contraria a donde se halla su nido oculto en el suelo y cuando el depredador intenta cazar al enfermo alzan el vuelo alcanzando su deseo de salvar a sus polluelos. Por último, algunas especies, como las abejas, parece que también comunican la situación de las posibles fuentes alimenticias a sus compañeras mediante movimientos codificados en la especie. De todas maneras, tales actitudes y comportamientos parecen prefijados en la especie y son, por tanto, casi automáticos e inevitables. Es decir, si seguimos la idea de Fodor que antes resumí, se trataría de elementos totalmente modularizados.

En cambio, la comunicación humana mezcla elementos modularizados (como lo es el código lingǘstico que se ha adquirido a partir de la experiencia) con procesos que no se pueden considerar tales, ya que necesitan un tipo de operaciones inferenciales que no son ni automáticas, ni evidentes en cada caso concreto, con lo que, no sólo apuntamos a elementos existentes o deseos, sino a cualquier tipo de representación mental que tengamos almacenada privadamente en nuestra mente y que, de esta forma, se ponga de manifiesto con el fin de que otros individuos puedan llegar a compartirla. Como se puede percibir en esta descripción somera de los distintos casos de comunicación, parece que existe un camino evolutivo que nos lleva desde la mera transmisión de información, hasta los casos complejos de comunicación humana.

Sperber y Wilson, en esta obra que acabo de comentar, ya apuntaron que, por tanto, la herramienta lingüística humana es sólo eso, una herramienta que facilita y mejora la comunicación entre los individuos de nuestra especie. Pero, por ello mismo, no se puede tratar dicha herramienta como si fuera la otra cara de la misma moneda en donde colocamos la comunicación. Por tanto, la última consideración que me llevó a imaginar la hipótesis de este trabajo es que, al no poder hacer coincidir totalmente nuestra herramienta lingüística con la manera que tenemos de comunicar, es muy dudoso que una de las caras de esa imposible moneda, la comunicación, sea la apropiada para describir el origen de nuestra herramienta lingüística.

Resumamos de nuevo las tres consideraciones básicas que fundamentan mi hipótesis:

1.La aparición súbita de la herramienta lingüística tal y como hoy la conocemos en nuestra especie no puede quedar inexplicada si queremos que la hipótesis que 
propongamos pueda resultar razonablemente descriptiva y explicativa.

2.La evolución de cualquier órgano mental ha de ser descrita a partir de las funciones cognitivas que éste realiza, no de sus características físicas materiales.

3.No es obvio que el origen de la herramienta lingüística humana tenga que ser imaginado a partir de actos comunicativos que paulatinamente irían añadiendo características de nuestra herramienta lingüística hasta dejarla totalmente configurada.

\section{Hipótesis CENTRAL DE ESTE TRABAJO A PARTIR DE LAS ANTERIORES CONSIDERACIONES}

\subsection{LOS NIVELES DE ADECUACIÓN CIENTÍFICA PREVIOS}

Como vimos anteriormente, en un análisis científico hemos de adecuarnos a unos niveles de explicitud que, en general, ni siquiera se postulan, porque son tan evidentes en los campos de la física y demás ciencias naturales que no se habían explicitado antes. Por ello, cuando lo que tratamos de hacer es un análisis científico serio de objetos o eventos mentales, su clarificación es conveniente para asegurar dicho carácter a nuestras disquisiciones. Un pensamiento científico ha de alcanzar tres niveles para ser adecuado (Cfr. N. Chomsky: 1957).

\subsubsection{EL NIVEL OBSERVACIONAL}

Para empezar a pensar científicamente, al menos hay que determinar qué objeto, hecho o evento vamos a tratar de estudiar. Hay pensamientos que no llegan ni siquiera a este tipo de constreñimiento porque, cuando se trata de ideas tradicionalmente recibidas, es a veces muy difícil apuntar qué tipo de realidades abarca la palabra que ha legado la tradición. Tenemos un ejemplo muy evidente al que ya apuntamos anteriormente cuando mencionamos el debate entre Hauser, Chomsky y Fitch (de ahora en adelante, HC\&F) con Pinker y Jackendoff (de ahora en adelante, P\&J). Vamos a repetirlo, poniéndolo en nuestro idioma ¿Qué entendemos cada una/o con los términos idioma, lengua o lenguaje? ¿Son palabras sinónimas? En caso negativo, ¿somos capaces de distinguir las diferencias? Un pensamiento científico tendría que empezar clarificando este punto. Lo haremos más abajo.

\subsubsection{EL NIVEL DESCRIPTIVO}

Una vez que tenemos más o menos claro el lugar ${ }^{20}$ al que apuntamos con un determinado vocablo, el paso siguiente es el de describir cómo funciona o de qué manera aparece dicho objeto, estado o evento. Hay, por supuesto, muchas formas de describir algo. Una de ellas es utilizando nuestro idioma materno lo más claramente posible. Pero como este medio tiene bastantes problemas de explicitud, algunos científicos prefieren desarrollar un medio propio que intente superar dicho problema. El sistema lógico es una de las posibilidades; otro ha sido

${ }^{20} \mathrm{O}$, más adecuadamente, al espacio semántico. 
el de las matemáticas; actualmente, los algoritmos informáticos también pueden servir. O crear algoritmos propios, como hizo, por ejemplo, Chomsky con la formalización de sus descripciones en baterías de operaciones sintáctico-léxicas.

Sería posible afinar este punto determinando los tipos de descripciones centrados en los estadios que, a su vez, propuso David Marr (1982) para los objetos y procesos mentales.

\subsubsection{Estadio computacional}

En este primer estadio hay que tratar de explicar claramente las operaciones (o computaciones, si aceptamos el neologismo) que han de ocurrir para que un determinado objeto, hecho o evento tenga lugar. Si logramos dar este primer paso con éxito, podríamos, en teoría, simular (o, en otras palabras, crear un modelo) que funcionara de la misma manera que aquello que pretendemos estudiar.

\subsubsection{Estadio representacional}

Las operaciones básicas arriba descritas pueden sin embargo estar representadas por cada grupo cultural de manera distinta con lo que posiblemente actúe sobre y con ellas de forma diferenciada y determinada por tales representaciones culturales.

\subsubsection{Estadio implementacional}

Este último estadio, denominado con tal anglicismo, se refiere a cómo cada cultura ha implementado (o, si se prefiere, ha materializado) aspectos cognitivos que se transmiten culturalmente y facilitan la realización de las operaciones básicas del evento.

\subsubsection{NIVEL EXPLICATIVO}

Mucha ciencia, y sobre todo la que trata de temas asociados al funcionamiento de la mente humana, se da por contenta en el nivel descriptivo, cuando lo consigue. Parece que explicar la razón de ser de ciertos fenómenos humanos está en la mente divina y por tanto más allá de nuestra capacidad explicativa. Sin embargo, y por una parte, a partir de los trabajos de Charles Darwin, a mediados del siglo XIX, la naturalización de los mecanismos biológicos que nos han hecho como somos es un objetivo científico serio. Por otra, parte, cuando Alan Turing, a mediados del siglo XX, imaginó la manera de mostrar cómo la materia podía procesar, guardar y manipular información, ideando su máquina abstracta, el camino metodológico para naturalizar la mente humana empezó a mostrar muchas posibilidades de éxito, surgiendo un marco teórico dedicado a ello en cada una de las tradicionales ciencias humanas: el cognitivismo y su abanico de disciplinas, e.g., la Lingüística cognitiva, la Psicología cognitiva, la Filosofía cognitiva, la Antropología cognitiva, etc.

\subsection{INTENTO DE ALCANZAR LOS NIVELES DE ADECUACIÓN EN EL OBJETO DE ESTE ESTUDIO}

Como quedó ilustrado en el debate entre HC\&F con P\&J, cuando se habla de la evolución 
del lenguaje, no resulta muy claro a qué nos estamos refiriendo. En consecuencia, las hipótesis que se han propuesto (o, al menos, las que yo conozco) parece que mezclan elementos y funciones de distintos objetos mentales, con lo que resulta difícil (si no imposible) alcanzar una necesaria clarificación descriptiva posterior.

Se da el caso que en español tenemos en este punto una riqueza terminológica que no existe en otros idiomas. Así, hay en castellano tres vocablos, los de idioma, lengua y lenguaje, que no están claramente delimitados, ya que nuestra tradición de estudios lingüísticos no se ha preocupado de hacerlo y emplea las tres palabras casi sinónimamente, con algunas matizaciones. Por eso, es fácil oír hablar del lenguaje de los animales; menos corriente es mencionar la lengua de los animales (a no ser que se trate del órgano carnoso alojado en su boca); y casi imposible apuntar al "idioma de los animales". Lo mismo ocurre con el lenguaje de los gestos, por ejemplo. En cambio, se dice escuela de lenguas o de idiomas, casi indistintamente; o se habla de las lenguas vivas y muertas (pero no de los idiomas muertos), de la filología de la lengua inglesa o del idioma inglés. Y seguro que hay más casos de indecisión que ahora se me escapan...

Como se ve, pues, existe una imprecisión real a la hora de apuntar al objeto del que estamos hablando cuando nos referimos a lenguaje, lengua o idioma ${ }^{21}$. Por ello. Propongo que utilicemos la palabra lenguaje para apuntar a algo que no es básicamente un medio de comunicación. Utilizaré esta palabra para señalar a la capacidad que tienen algunos organismos (entre los que se encuentra el ser humano, aunque no es el único) de representar simbólicamente aspectos del mundo en su interior. Esta capacidad tiene alto valor de supervivencia, por cuanto los individuos que la poseen son capaces de manipular las representaciones mentalmente y predecir sus posibles resultados positivos o negativos. Diríamos, por tanto, que el lenguaje es, en realidad, un dispositivo cognitivo cuya función básica es la de representar, almacenar, ordenar y manipular elementos del entorno en el que se mueve cada individuo. En otras palabras, el lenguaje no es un subsistema de la cognición humana sino su mecanismo esencial. Sin lenguaje no hay cognición y viceversa.

En informática, por otra parte, cuando se habla de lenguajes no se hace esta identificación lenguaje-comunicación, por lo que al explicitar este primer nivel de adecuación, al menos unificamos los dos conceptos (el natural y el informático) de lenguaje, ya que en ambos casos estamos apuntando a lo mismo y no a ningún proceso comunicativo.

Todos sabemos, sin embargo, que algunos animales tienen otra capacidad cognitiva: la de comunicarse entre sí, intercambiando mensajes. Es en este segundo sentido en el que se emplea, por ejemplo, la expresión de lenguaje animal. Lo malo de esta denominación es que, si no se tiene muy clara la función básica del lenguaje como proceso formalizador y manipulador de representaciones, se llegan a confundir ambas funciones equiparando lenguaje y comunicación (y no, repito, lenguaje y cognición) como si fueran dos caras de la misma moneda. Por tanto, vamos a mantener claramente separados estos dos procesos al ir creando nuestra hipótesis evolutiva.

Los seres humanos (y muchos animales) han aprendido a comunicar ayudándose, no sólo de gestos y movimientos, sino también de sonidos que producen con su aparato respiratorio y

\footnotetext{
${ }^{21}$ Esta asombrosa indefinición que existe en los estudios lingüísticos españoles podría provenir, a mi entender, de la gran influencia lingüística anglosajona, sobre todo americana, en esta materia. En inglés solamente existe una palabra, language, que engloba a las tres que tenemos nosotros. La filología alemana, que también ha influido en la española, tiene así mismo sólo una palabra para designar este campo, Sprache. La única distinción posible es la de la lingüística francesa, en donde existen dos (pero no tres) palabras distintas: langue y langage. Quizá es por esto que es más fácil de distinguir el lenguaje de la lengua y del idioma que la lengua del idioma.
} 
su boca. No obstante, los sonidos que emiten los animales en sus intentos de comunicación suelen ser muy estereotipados, aunque es evidente que su liberación de patrones preestablecidos es mayor a medida que se complica el cerebro de la especie en cuestión. Como, debido a la mitología reinante, nuestro cerebro se considera el más evolucionado de todas las especies, la libertad que tenemos los humanos en la proferencia de sonidos parece ser absoluta en principio. Sus evidentes limitaciones se consideran producto de coordenadas meramente sociales que son las que transmiten los idiomas de generación en generación.

En efecto, existen innumerables idiomas humanos que no tienen nada que ver unos con otros, con lo que, para muchos, esa diversidad demuestra que la mente humana carece de patrones genéticos inscritos en ella ${ }^{22}$. Es, en palabras de Aristóteles, como una tabla vacía (tanqvam tabula rasa) en la que los estímulos sociales van grabando su influjo.

Sin embargo, hay otra manera de explicar esta gran diversidad idiomática sin violentar las leyes de la evolución. Precisamente por ello, es la que vamos a adoptar aquí, una vez que la hayamos explicado.

Se ha demostrado palpablemente, por ejemplo, que las operaciones estereotipadas de los ordenadores se pueden corregir (es decir, parecen mucho más libres) si se ponen a trabajar varios ordenadores en paralelo, llegándose incluso a resolver problemas que ningún ser humano había podido solventar - con lo que queda excluida la llamada objeción de Lovelace (ver más abajo) según la cual un (repito, UN) ordenador solamente realiza aquello para lo que lo programó su creador. Es decir, es posible que una serie de ordenadores trabajando juntos consigan resultados totalmente distintos de otro grupo de ordenadores enfrentados con el mismo trabajo. ¿No es ésta la libertad de la que se habla?

Por tanto, la especulación que hagamos en este punto puede ser de signo contrario a la que imagina la tabla rasa. Porque, en efecto, la enorme diversidad de idiomas humanos podría no deberse al caso bastante insólito, desde el punto de vista evolutivo, de que la mente humana carezca de estructuras especie-específicas, sino más bien al contrario. Que nuestra mente tenga muchas más estructuras mentales heredadas en su evolución que ningún otro cerebro animal y que, precisamente por ello, es capaz de realizar muchas más operaciones; así, la múltiple interacción de muchas de estas estructuras sería la que ha permitido la aparición de esa enorme cantidad de idiomas conocidos con características aparentemente tan diversas ${ }^{23}$. Tengo claro, como ya dije antes, que la historia de los idiomas humanos no se puede equiparar científicamente con la del origen y evolución de nuestra herramienta lingüística. En cambio, lo que de ahora en adelante voy a llamar lengua es precisamente el conjunto de estructuras mentales que, de alguna manera, limitan esa libertad aparentemente total de los idiomas humanos. Se trata, esta vez sí, de estructuras que están inscritas en la especie humana por la evolución y son las que hacen que nuestra manera de ayudarnos a comunicar por medio de sonidos sea totalmente distinta de la de los demás animales. Son también las que permiten la adquisición natural del idioma en el que estamos inmersos al nacer, por lo que algunos (una vez que Chomsky la bautizó de esa manera) la conocen como dispositivo de adquisición lingüística o, en siglas, $D A L$ (que en inglés es precisamente al contrario, $L A D$, de language acquisition device). Prefiero llamarlo lengua porque con este término englobo tanto (a) los constreñimientos a la libertad lingüística como (b) la facilidad relativa que tiene el ser humano para crear su propia

22 Cf. E. Bernárdez, 1999. Especialmente, el capítulo 7.

23 Cf., J. Barkow, L. Cosmides y J. Tooby (eds.), 1992. Especialmente, el capítulo 3. 
gramática con casi nada.

¿Qué quiero decir con casi nada?

Sencillamente que, también en este caso, las apariencias engañan. En efecto, nos puede dar la impresión de que la gramática que aprenden las/los bebés la van imitando a medida que la oyen en el idioma materno en el que se están desarrollando, al igual que imitan los sonidos que se convierten en palabras para designar conceptos.

Para empezar, el éxito de esta pretendida imitación es tan absoluto que destruiría la moral de cualquier lingüista o enseñante de idiomas que se pusiera a pensar en ello. Porque la asombrosa habilidad de la/el bebé es, primero, la de ser capaz de deducir una a una las reglas gramaticales abstractas a partir de los sonidos que oye proferir a su alrededor. Se trata de algo (i.e., la creación de una gramática adecuada) que, todavía, no se ha podido completar de manera consciente, a pesar de los innumerables investigadores que se han dedicado a este tipo de fenómeno desde, al menos, hace medio siglo, hasta hoy en día. Y, en cambio, todas las personas lo hemos conseguido inconscientemente en los tres o cuatro primeros años de nuestra vida.

Pero hay más: por ejemplo, y como apunta S. Pinker (1994), las/los hijas/os de personas que hablan un segundo idioma mal aprendido entre ellas/os (caso de las/los esclavas/os negras/os de distintas etnias transplantadas/os al Nuevo Mundo) que algunas/os llaman macarrónico ${ }^{24}$ adquieren un idioma nada macarrónico, sino absolutamente similar a los demás idiomas humanos, que recibe el nombre de criollo o, más corrientemente en su acepción francesa, créole. Está claro que estas/os niñas/os no han podido imitar esa manera de construir su nuevo idioma, lo que prueba la fuerza de las estructuras mentales que llamo lengua.

La lingüística chomskyana y sus derivaciones trata sobre todo de estudiar las características de este tipo de estructuras mentales, determinando los principios que la rigen y lo que, en la jerga de la teoría, se llaman parámetros, es decir, posibilidades abiertas de elección entre dos o más estructuraciones.

Llegados a este punto, es fácil indicar que lo que hasta ahora he denominado berramienta lingüistica bumana está compuesto por tres objetos mentales, dos de los cuales han sido resultado de nuestra evolución (el lenguaje y la lengua), mientras que el otro (el idioma), aunque tiene una historia ramificada en varias direcciones, no se puede considerar realmente producto de ninguna evolución más que en un sentido muy metafórico y, por ello, capaz de crear malentendidos o incluso confusiones de importancia.

Como vemos, con sólo tomarse en serio el primer nivel de adecuación científica, es posible desbrozar el camino a seguir en nuestro análisis. Sin embargo, hay que seguir podando el complejo mundo en el que nos movemos, ya que si tenemos en cuenta el nivel descriptivo en su sub-nivel representacional tendremos que subvertir la representación socialmente muy bien diseminada entre nosotros de la moneda con las dos caras: la de la/el lengua(je) por un lado y la de la comunicación por el otro. El primer resultado que me gustaría alcanzar con este trabajo sería el de lograr cambiar la concepción de dicha moneda imaginada por otra con sus correspondientes dos caras, también: la de la/el lengua(je) por un lado y la de la cognición -en vez de la comunicación- por otro.

\footnotetext{
24 Cf. nota 1.
} 


\subsection{LA EVOLUCIÓN NO UNITARIA DE LA HERRAMIENTA LINGÜÍSTICA HUMANA}

Una vez que hemos sido capaces de apuntar a tres conceptos con los tres términos del español, lenguaje, lengua e idioma, tenemos necesariamente que tratar de imaginar cómo evolucionaron cada uno de ellos pos separado hasta convertirse en esta herramienta lingüística que nos ayuda tanto a afinar nuestros esfuerzos comunicativos hoy en día.

Mi idea es que el ser humano desarrolló (o heredó de otra especie, ahora no hace al caso) un lenguaje, en el sentido mental que propuse, al conseguir formalizar algunos estímulos para almacenarlos y manipularlos en su mente. Mi impresión es que dicho lenguaje podría caracterizarse en un principio y de manera metafórica como analógico, ya que lo que ahora llamamos imágenes están en la base del desarrollo mental. Es decir, el proceso formalizante en sus comienzos lograría poco a poco crear representaciones similares ${ }^{25}$ a los objetos reales fijando en la memoria la información más relevante de cada uno de los estímulos que se percibieran. Una vez que este proceso estuviera bien avanzado, es posible que surgiera la facultad cognitiva de incrustar algunas representaciones de objetos perceptibles dentro de otros para ir creando categorías que, a su vez, se formalizaran en elementos más abstractos, hasta conseguir otras representaciones de entramados de relaciones, aumentando poco a poco la abstracción ${ }^{26}$. Ignoro si esta abstracción conseguida sería el vehículo para empezar a representar deseos y posibles maneras de actuar para alcanzarlos, pero lo cierto es que esas representaciones se fueron haciendo posibles a lo largo del desarrollo mental de los humanos. En este punto, me atrevo a formular una idea que requeriría un estudio más profundo y serio. El nacimiento de este lenguaje podría estar ligado a la necesidad de organizar el entorno y hacerlo manipulable día a día, función que, según parece, correspondía más a la labor de las hembras de la especie que a los machos. Por eso, aunque sea arriesgado proclamarlo, me parece provocativamente ajustado afirmar que el lenguaje se originó sobre todo en la mente de las primeras mujeres de nuestra especie (o de las hembras de nuestros antecesores humanos).

Por otra parte, la dedicación a la caza que, también parece ${ }^{27}$, era una tarea masculina, exigía la coordinación de comportamientos de los componentes del grupo cazador, la cual, en principio, no tenía por qué diferenciarse de los comportamientos comunicativos de las bandas de otras especies que también cazan en grupo. Es decir, existirían una serie de indicios en los que podían basarse los individuos del grupo cazador para realizar su labor conjunta, algunos de los cuales serían interpretables por los demás con arreglo a claves espaciales y sencillas operaciones de inferencia mental (i.e., si X está corriendo allí, le cerrará el paso a la presa y yo podré darle alcance; si Z se esconde allá, tendré que hacer lo posible por que la presa vaya hacia él, etc.), o de otro tipo, incluso sonoras, con arreglo a los diversos gritos que los cazadores emitieran a lo largo de su caza. Estos gritos o gruñidos quizá no fueran voluntarios en un comienzo, sino producto de la actividad cazadora; sin embargo, poco a poco, es muy probable que algunos de ellos se fueran haciendo indicadores útiles para los demás, con lo que

\footnotetext{
${ }^{25}$ Con todas las salvedades que el concepto de similaridad pueda mostrar al tratar de analizarla causalmente.

${ }^{26}$ Cf. A. Rivière, 1982. Uno de los posibles resultados sería la invención del tiempo. En efecto, si aquellas mentes lograban incrustar en representaciones abstractas como [ANTES], [AHORA] y [DESPUÉS], representaciones concretas de deseos como [tengo hambre], [estoy satisfecha] y [dormir], es fácil imaginar cómo se habría producido la conciencia del paso del tiempo en nuestra especie-que no parece existir en las demás. Esto requiere, naturalmente, un estudio bastante más pormenorizado que el presente.

27 Aunque hay muchas dudas a la hora de establecer este tipo de división de funciones entre las mujeres y los hombres.
} 
se iría creando un código que, al compartirse y ser usados intencionadamente, facilitaría mucho la coordinación de las actividades del grupo cazador.

Da la impresión de que los investigadores del origen del lenguaje se basan en esta probable formación de códigos de señales sonoras para postular que ése y sólo ése pudo ser el origen de lenguaje humano. Un lenguaje que sería balbuciente en un principio, defectuoso y pobre en el estadio siguiente, hasta alcanzar la plenitud lingüística de la herramienta comunicativa que hoy creemos que es única en nuestra especie. Existe, sin embargo, un pequeño problema: nunca se ha encontrado un indicio de un idioma balbuciente, o de otro imperfecto, con lo que la opinión general es que todos los idiomas que se hablan actualmente en el mundo tienen todas las características que los hacen humanos; no se puede, por tanto postular que haya, hoy por hoy, idiomas que muestren primitivismos que, algunos atribuyen al supuesto protolenguaje que precedió a nuestra herramienta lingüística. Pero, a pesar de este nimio problema, muchos investigadores se han puesto a elucubrar, imitando, sin saberlo, al mulá Nasrudin ${ }^{28}$. En efecto, se ha llegado a proponer que, aunque no exista actualmente posibilidad de encontrar estos lenguajes imperfectos en ninguna parte (ni siquiera en culturas llamadas etnocéntricamente primitivas), el desarrollo lingüístico comunicativo propio de la evolución de cada individuo, o la formación de los llamados lenguajes créoles a partir de los pidgins, pueden servir de analogía explicativa para describir el desarrollo del lenguaje en la evolución de nuestra especie. Se busca bajo el farol de la comunicación la llave perdida del origen del lenguaje.

Lo absurdo de esta búsqueda queda patente ante dos tipos de consideraciones, una de ellas, absolutamente evidente, la otra, aunque forma parte de una hipótesis no aceptada universalmente, parece así mismo bastante probable. La primera consideración es que los pidgins surgen en los intentos comunicativos de personas que ya tienen un idioma materno y lo saben usar comunicativamente, por lo cual, las intuiciones de cómo comunicar lingüísticamente con los demás están absolutamente desarrolladas y eso no puede servir de analogía explicativa del origen especie-específico de lenguaje humano, ya que antes de que éste apareciera no existía ningún tipo de modelo previo de cómo usar un lenguaje como herramienta comunicativa.

En el caso de los inmaduros de nuestra especie es también obvio que en su entorno todas las personas a su alrededor usan las herramientas lingüísticas para comunicarse entre ellos e, incluso, a veces, con ellos, aunque, al principio, se usan más otro tipo de medios (caricias, gestos, sonidos fuertemente caracterizados por el tono de la voz, etc.) que sí podrían recordar y, por tanto, servir de modelo explicativo para indicar cómo empezó el ser humano a comunicarse con sus semejantes. Pero, además, aunque no todo el mundo lo acepta, no parece descabellado postular que todos los lenguajes humanos, precisamente por ser humanos, tienen unas características universales que es posible describir y catalogar de manera explícita; esto es, existe una gramática universal muy abstracta que forma parte del bagaje del genoma humano y que, por tanto, se hereda por todos los individuos de nuestra especie, haciendo posible que adquieran sus respectivos idiomas con pasmosa facilidad (cosa que no consiguen los individuos de otras especies, aunque algunos, fuertemente amaestrados, cual animalitos de feria o de circo, consigan con mucho esfuerzo usar símbolos inventados por los humanos para ajustar algunos de sus actos comunicativos). Sea como fuere, tampoco se nos antoja muy apropiada la analogía

\footnotetext{
${ }^{28}$ Una de las historias de este mulá, cuenta que alguien se lo encontró buscando su llave debajo de un farol, pero cuando le preguntó si la había perdido allí, éste contestó que no, que mucho más lejos, aunque como allí estaba demasiado oscuro y era imposible encontrarla, decidió hacerlo bajo la luz (cf. I. Shah, 1973).
} 
con este proceso de adquisición del idioma materno como un modelo apto para describir y tratar de explicar el origen del lenguaje en nuestra especie ${ }^{29}$.

Algunos investigadores, ante estos problemas, afirman como hemos visto que el lenguaje humano nació de manera súbita sin que exista ningún tipo de explicación posible sobre su origen. Se ha propuesto que este origen sería una casualidad como la de los arquitrabes arquitectónicos, según el famoso ejemplo de S. J. Gould (1993), causando no poca indignación entre los darwinistas que afirman que todo en la evolución de las especies es gradual y puede rastrearse, yendo paso a paso desde el momento presente hasta las épocas lejanas en que presuntamente apareció.

Este es otro pseudo-problema que también desaparece si se plantea teniendo en cuenta la SET a la que aludimos más arriba. ¿Por qué no postular que dos procesos distintos, dos funciones diferentes que tuvieron orígenes diversos se llegaron a unificar consiguiendo una función nueva, un proceso complejo, que es el de la utilización de nuestro lenguaje en simbiosis con el proceso comunicativo? Parece ser la solución a todos nuestros problemas, hasta ahora insolubles.

Sin embargo, es cierto que resulta bastante arriesgado, sobre todo si nuestro acercamiento a estas teorías biológicas es sólo el de personas de inteligencia corriente sin dedicación plena, metaforizarlas y emplearlas en otros campos que no son los específicos para las que fueron creadas. No obstante, como hemos visto, a menudo se recurre a dichas metáforas (i.e, los memes de Dawkins o la epidemiología de Sperber) que ayudan a ilustrar nuevas ideas que podrían ser productivas y predictivas. De hecho, parece que Lynn Margulis, en su lección ofrecida en agradecimiento por haber sido nombrada Doctora Honoris Causa de la Universidad de Valencia, apunta a esta posibilidad:

[...] la historia natural, ecología, genética y metabolismo de organismos macroscópicos debe de ser suplementada con un conocimiento preciso del metabolismo y del comportamiento de los microorganismos. La fisiología y la ecología microbianas son esenciales para la comprensión del proceso evolutivo. El comportamiento de los microorganismos dentro de sus propias poblaciones y en sus interacciones con otros determinó el curso de la evolución de la vida. El mundo vivo subdivisible en último término es el fundamento del comportamiento, desarrollo, ecología y evolución del mundo visible del cual formamos parte y con el cual evolucionamos. (La cursiva es mía) ${ }^{30}$.

Si aceptamos que en los procesos evolutivos, lo que ocurre a niveles microscópicos repercute $y$, a veces, parece que se repite a niveles macroscópicos, ¿por qué no aceptar la idea de que la complejidad de los sistemas orgánicos y funcionales podría surgir no sólo a partir de los procesos darvinistas de selección natural, sino también a partir de los procesos simbióticos cuya existencia parece hoy fuera de toda duda en el mundo microscópico?

\footnotetext{
${ }^{29}$ Obsérvese cómo esta distinción entre idioma materno y lenguaje humano es muy difícil de establecer usando el inglés o cualquier otro idioma que carezca de los tres términos que tenemos en español a los que antes me referí. En cambio, para nosotros, resulta meridianamente clara. Por lo que la comparación analógica al usar la adquisición de un idioma como pauta para explicar el origen del lenguaje se antoja mucho más inverosímil, puesto que se trata de dos procesos que nos representamos de manera radicalmente distinta.

${ }^{30}$ MARGULIS, L. (2002): Una revolución en la evolución, Valencia: Universitat de Valencia, p. 34.
} 
En pocas palabras y como colofón a este trabajo:

Por una parte se desarrolló la capacidad representativa de la mente humana, hasta que una pequeña mutación, la que permitió que las posibilidades recursivas de alguno de estos dispositivos mentales cuya presencia en otras especies parece clara, se multiplicara de manera exponencial en el caso humano, dando así origen al LENGUAJE.

Por otra parte, la necesidad de intercambiar información entre los individuos de las especies, dio como resultado el uso y posterior codificación de ciertos comportamientos, algunos de los cuales se fijaron en el genoma y otros, en cambio, se aprendían por la experiencia, que apuntaban a ciertos eventos u objetos, con lo que se dio inicio al proceso comunicativo.

Cuando ambas funciones se unieron, o por casualidad, como postulan Darwin y sus seguidores, o porque alguno de los individuos creyera que se trataba de un buen truco, como dice Dennett, y lo aplicara con notable ventaja para su seguridad, desarrollo y posibilidad reproductora, surgió esta función netamente humana de aplicar productivamente elementos formalizados del lenguaje mental a la señalización, no sólo de objetos y eventos, sino y sobre todo, a la de estados mentales individuales que de esa manera se consiguen hacer públicos en este proceso único que parece ser la comunicación lingüística humana. El resultado fue tan beneficioso que, a la larga, se convirtió en hereditario y hoy en día todos los seres humanos son capaces de usar este proceso simbiótico complejo como si estuviera producido por un verdadero órgano especializado para este fin.

Queda mucho, por tanto, que investigar y que imaginar, ya que no es fácil establecer cómo se desarrollan las representaciones del mundo en las mentes, ni cómo se relacionan entre si en entramados complejos que se incrustan unos en otros formando estructuras significativas. Pero, al menos, nos hemos separado del farol de la comunicación bajo el que no hubiéramos podido jamás encontrar una verdadera descripción o explicación de los orígenes lingüísticos. Y, además, es posible investigar comparativamente las distintas maneras de comportarse comunicativamente en otras especies para así determinar qué sigue siendo similar en nuestros comportamientos y cuáles han sido los cambios ventajosos que la especie humana a podido conseguir con nuestra manera específica de comunicarnos lingüísticamente, una vez realizada esta simbiosis entre ambos procesos.

\section{REFERENCIAS}

AUNGER, R. (ed.) (2000): Darwinizing Culture: The Status of Memetics as a Science, Oxford: Oxford University Press, p. 163.

BARKOW, J. H., COSMIDES, L. y J. TOOBY (eds.) (1992): The Adapted Mind, Oxford: Oxford University Press.
BERNÁRDEZ SANCHÍS, E. (1999): ¿Qué son las lenguas?, Madrid: Alianza Editorial.

BICKERTON, D. (2003): "Symbol and structure: a comprehensive framework for language evolution", Christiansen, M. H. y Kirby, S. (eds.): Language Evolution: The States of the Art, Oxford: Oxford University Press, pp. 77-93.

BICKERTON, D. (2009): Adam's Tongue, New York: Hill and Wang. 
BURGE, T. (2010): “A real science of mind”, New York Times (19-XII-2010): http://opinionator.blogs.nytimes.com /2010/12/19/a-real-science-of-mind/.

CHOMSKY, N. (1957): Syntactic Structures, La Haya: Mouton.

CHRISTIANSEN, M. H. y KIRBY, S. (eds.) (2003): Language Evolution, Oxford: Oxford University Press.

FITCH, W. T., HAUSER, M. D. y CHOMSKY, N. (2005): "The evolution of the language faculty: clarifications and implications", Cognition, 97, p. 180.

FODOR, J. (1983): Modularity of Mind, Massachusetts: M.I.T Press.

FODOR, J. (1985): "Précis of modularity of mind", The Behavioural and Brain Sciences 8, pp. 1-12.

GOULD, S. J. (1993): "Fullfilling the spandrels of world and mind", Selzer, pp. 310-36.

PINKER, S. (1994): The Language Instinct, London: Penguin Books.

RIVIÈRE GÓMEZ, A. (1982): Razonamiento y representación, Madrid: Siglo XXI de España, Editores.

SAGAN, L. (1967): "On the origin of mitosing cells", Journal of Theorethical Biology, 14 (3), p. 255.
HAUSER, M. D., CHOMSKY, N. y TECUMSEH FITCH, W. (2002): "The Faculty of Language: What Is It, Who Has It, and How Did It Evolve?", Science, 298:1569-1579.

MARGULIS, L. (2002): Una revolución en la evolución, Valencia: Universitat de Valencia, p. 34.

MARR, D. (1982): Vision: A computational investigation into the Human Representation and Processing of Visual Information, San Francisco: Feeman.

MAYR, E. (1984): "What is Darwinism Today?", Proceedings of the Biennial Meeting of the Philosophy of Science Association, 2, p.145.

PINKER, S. y JACKENDOFF, R. (2005): "The Faculty of Language: What's Special about it?”, Cognition, 95(2), p. 201.

SELZER, J. (ed.) (1993): Understanding Scientific Prose, Madison: Wisc. University of Wisconsin Press.

SHAH, I. (1973): The Exploits of the Incomparable Mulla Nasrudin, London: Pan Macmillan (Picador Books).

SPERBER, D. (2000) "An objection to the memetic approach to culture", Aunger, R. (ed.): Darwinizing Culture: The Status of Memetics as a Science, Oxford: Oxford University Press, pp. 163-173. 